\title{
Moving Right Along: Changes in Staffing, Functions, Workstation Setup, and Personnel
}

\section{Douglas Duchin}

Changes in staffing, functions, workstation setup, and personnel training in the Technical Services Department of the Newman Library at Baruch College of the City University of New York over the last ten years are reviewed. In particular, the development of an integrated workstation, the expansion of job responsibilities, and the retraining of personnel are discussed.

$\mathrm{n}$ the continuum of library technical services, we're moving right along. In the last ten years at Newman Library, we've moved from a dependence on local practice to a sense of community and a new emphasis on expediency. Not only have we begun using the new technological tools, but we have been imbued with a feeling of team playing, a new sense of production, and a we're-all-in-this-together attitude. What's happening here may be a reflection of what's happening throughout the information-processing industry. The emphasis on speed, production, and patrons' needs has given us a new focus, and our automated workstations have given us the tools to achieve these goals.

In the last ten years we have come to rely not only on the national databases, such as OCLC Online Library Computer Center, Inc., and the Library of Congress (LC), but even more on clerical interpretation and manipulation of data. We've developed more speed, more cooperation with reference and circulation, and more acceptance of their input. Along the way we picked up a lot more self-assurance as team players and got rid of a lot of the ivory-tower image.

City University of New York, of which Baruch College is a part, brought up the NOTIS system in 1988, primarily with the online public catalog available, and called it CUNY+. It was a major changing point in our lives, although I speak of an event that took place a couple of years before I arrived. At that point, in 1988, our Technical Services Department consisted of a couple dozen people handling catalog cards and paper orders in a fairly standard manner. Our orders were transmitted electronically through OCLC, which also kept accounts for us. The department was highly structured and compartmentalized. Catalogers cataloged. Acquisitions staff acquired. Few, if any, staff members had overlapping responsibilities or training —although almost all could perform copy cataloging.

The staffing consisted, specifically, of 6 full-time professionals-three catalogers, 1 serials librarian, 1 acquisitions librarian, and $\mathrm{l}$ head of Technical Services.

Douglas DuChIN (ddubb@cunyvm.cuny.edu) is Head, Technical Services, Newman Library, Baruch College, City University of New York. This article was originally presented at the ALA Annual Conference, July 8, 1996, New York City. Manuscript received November 8, 1996; accepted for publication January 30, 1997. 
Most had no responsibilities outside of Technical Services. In addition, there were at least 12 full-time clerical staff and many student assistants. The organization was structured, which meant that input and output were standardized and predictable. Statistics were kept manually, a backlog in cataloging had developed, and serials payment tracking was vague.

\section{Systems Changes}

Changes in personnel, machinery, or even surroundings often have the happy ability to grease the wheels and get things moving in more productive ways. Thanks to those changes, only 9 people, including 3 professional librarians, handle almost as much material as it took two dozen to handle 8 years ago. We handle it faster, too.

The first and probably most visible change was the introduction of the NOTIS Generic Transfer and Overlay (GTO), which ran on an IBM PS/2 and had serial connections to OCLC, to NOTIS, and to the GTO through a controller. The GTO allowed for instant transfer of bibliographic information from OCLC to our NOTIS system, cutting in half both the number of workstations and the processing time needed.

Ten years ago, acquisitions was limited to using only LC-cataloged or -modified data as the basis for ordering. As it became apparent that this was a bottleneck, we retrained acquisitions staff to locate, recognize, and use any reasonable record on OCLC. For materials not on OCLC, we decided to place all responsibility for creating a preliminary bibliographic record at the acquisitions level. The staff were taught, in a very short period of time, to identify essential elements of the order request and to enter them in MARC-tagged format. Since the cataloging staff researched every title on OCLC upon receipt, almost any level of cataloging would have done for an acquisitions record. In spite of this sudden departure from standard practice, the world did not come to an end.

Then we moved into an incredible new building in 1994, and when the dust settled, we found that we had fully integrated automated workstations and a head of Technical Services, Ida Lowe, who was a strong advocate of cross-training and integrated functions. Under Lowe's direction, all workstations were designed to be standard and interchangeable, which meant that staff members did not have to move from their desks to learn a new function and integrate it into the workflow. Much of what happened did so at the university level, not at the library level, as the university provided us with the necessary resources. We cut our reliance on OCLC as much as possible and began accepting records from other libraries available on our system. The university made the Library of Congress Resource File (LCRF) available at every workstation, giving us a pretty good bibliographic record for $95 \%$ of the books we ordered, without our having to tap into another utility. Additionally, the university provided us with a tape-loaded access to OCLC, which helped speed the process of uploading our new acquisitions into OCLC on tape and cut personnel costs. Currently, every staff workstation in the library has access to our own online catalog, OCLC, our CD-ROMs (including BIP Plus), the LCRF, the Internet (including the Web, e-mail, gophers, and FTP), electronic publisher catalogs, vendor databases, and virtually every major library catalog in the world through a Windows environment. The new fully integrated workstation provides all the tools of the trade and makes the job easier, more accurate, and much faster. The workstation also provides services that enhance personal growth and education such as research indexes and abstracts, some full-text materials, and so on, which are used by the staff in furthering their own formal education.

In addition, since our selectors use these tools as well, almost every order that comes to us has the potential of providing us with excellent bibliographic data. One of the next steps is to electronically link that order directly into the acquisitions process and perhaps provide a Web-accessed materials order form and make it available to all faculty and students. 


\section{Personnel Changes}

While we updated our electronic wizardry, we also focused on personneltheir attitudes, training, reporting responsibilities, and authority. Our new and enlarged public service area had absorbed not only some professional librarians from our Technical Services staff but clerical staff as well. Under the head of Reference, we developed a staff of "rovers" and "reference assistants." These were Technical Services staff members who assisted patrons within carefully defined parameters in the library's public service areas. By using the end products of their Technical Services work alongside patrons, the staff became very aware of the impact of their work. Incomplete or confusing information suddenly became very obvious. Work well done became a pleasure to use. The small staff in Technical Services expanded their horizons and knowledge, while the distinction between Public and Technical Services was blurred.

Irregular workflow, cash flow, and book selection can create a pig-in-the-python effect in acquisitions and cataloging. The resulting fluctuation in the volume of work creates a need for a flexible staff who can perform several functions. To develop this staff, we focused on the interrelationship of the roles of acquisitions and cataloging and emphasized the similarities in selecting the perfect record whether it was for acquisitions or for cataloging. A program for basic copy cataloging training was developed, along with a work manual. At the completion of the training, and with only two of the staff working part-time at copy cataloging, we were back up to speed within a month.

I feel strongly that we were able to do this so well because of changes in attitude. We made sure that supervisors were accessible to staff at all times. We made sure that staff members were aware of patron needs. We provided the best possible tools for moving materials quickly, and we emphasized speed without loss of quality. Above all, we showed respect to the staff. Since we are within a strong union situation, it is almost impossible to reward staff with promotions and raises. Consequently, it is essential that we reward them as best we can-respect, praise, pizza, and pitching in all seem to work well for us.

What I found very heartening is that we were able to do this as we added functions to the department. Streamlining and reduced budgets left us with free time, so we took on binding, preservation, periodical check-in, and current awareness services as we reduced staff. I can only attribute the success to a sense of team spirit and increased electronic access.

\section{Personnel Training}

On the positive side, as we changed, acquisitions jobs became enriched, broadened, and varied; by expanding the parameters of what they did and by improving the tools with which they worked, the staff took on more responsibility and authority. The staff were recognized for their knowledge and ability, and, finally, the borders between Technical Services and Public Services softened. They are not completely dissolved and probably will not be as long as one is assigned to one department or the other, but they are definitely softened. The job reassignments in both Public and Technical Services acquainted staff with all aspects of service and with the flow of materials through the library. Seeing what becomes of materials as they move through the many processes in the library gives new meaning to the slips and forms and rules of entry in acquisitions and cataloging.

On the negative side, there was definitely a sense of confusion and loss of job security as roles and responsibilities changed rapidly. The workload increased for management as we prepared for the changes. The most difficult obstacle, however, was overcoming the implication that things had not been done well before the changes. In reality, things had been done very well before the changes, given the limitations of equipment.

What did we do to help the staff through the changes and did it work? At times, many times, it was very obvious that none of us had gone beyond Management 101. Nevertheless, we structured training for the staff, complete with work sheets, rules, handouts, and practice sessions, and the Central Office of Library Services for 
the university backed us up with additional training sessions. Through it all, the management of the department was encouraged to take a proactive teaching role. Did it work? Yes, but it could have been better. If we were doing it over, we would have created additional ready-reference tools in an easily used package or looseleaf folder. We would definitely have looked into better training follow-up methods, and we would have tried to evaluate the training as we went-a perspective that is hard to achieve when you're doing the training yourself.

As for advice to others about to embark on such changes, I suggest you know why you're changing and believe in what you are doing. This gives you tremendous credibility and makes all transitions much easier. Be sure you keep everyone informed. Tell everyone why changes are being made and show how they will improve the library and the individual job. Plan your training, test it, and retest it in field situations before implementation, if possible. Don't assume that everything you have written is brilliantly clear or even applicable. It is important to pitch in and be very visible. Develop some sense of rapport with every staff member and keep motivating even when the immediate job is done. And never rest on your laurels.

\section{MOVING TOWARD THE FUTUhE}

Where are we going from here? The City University of New York is strongly considering centralizing the acquisitions and cataloging technical services functions for our nineteen colleges, which changes not only the game but the ballpark as well. The centralization of these services will very likely be the next step, but regardless of which way we go, we're going to come back to the basics we developed as we cut staff, added workstation capabilities, and managed training in the personnel area, and they are: Know why you are changing and believe in what you are doing. Try everything first yourself and ask your fellow wizards for advice. Train, evaluate, and retrain. Keep visible and keep motivating, even when you think the job is finished. Work with your staff, be part of your staff, and never rest on your laurels. 